\title{
Is the Uses and Gratifications Approach Still Relevant in a Digital Society? Theoretical and Methodological Applications to Social Media
}

\section{Anabel Quan-Haase*}

University of Western Ontario, Canada

A wide range of new theories, approaches, and methodologies have been proposed as a response to the changes occurring in the digitization of content, the creation and distribution of digital artifacts (e.g., documents, images, and videos) and the increasing production and dissemination of news on the Internet. These new trends have also motivated scholars to revive traditional theories in the field of mass communication and journalism, which could aid in examining digital communication. In this editorial note, the uses and gratifications approach $(U \& G)$ is presented as a theoretical lens and empirical means for studying how audiences engage with digital media. $U \& G$ provides a unique perspective on digital media as it stresses the relevance of media in the context of everyday life, examining uses, gratifications sought and obtained, and media practices over time. U\&G can help address critical research questions that emerge as individuals become further networked and embrace digital technologies for communication, information exchange, and content creation. Research questions that a U\&G approach to social media can address include:

- How are information and news from various sources diffusing through social media?

- What social media sites and services are relevant for individuals to keep up-to-date with local and global news?

- How satisfied are users of social media sites with the information they receive in terms of accuracy, relevance, currency, etc.?

- What gratifications do individuals obtain from different information sources and social media platforms on the Internet?

The U\&G approach allows examining two different sets of questions. The first set of questions revolve around what types of media users employ and the second set is concerned with why users adopt these specific tools and services. Addressing research questions about why people adopt diverse social media sites and services into their communication and socializing practices, routines, and habits has become increasingly relevant. Data collected by the Pew Internet and Everyday Life Project in 2011 show that social media are being adopted by all age groups in North America, with 64 percent of adults [1] and 80 percent of youth using a social network site (SNS) [2]. Similar trends are observed in other parts of the world. When examining the usage patterns of young people, the reliance on social media is high. Of those teenagers who use SNS, 40 percent log on to a site several times a day and 24 percent about once a day [2]. Quan-Haase and Young (forthcoming) [3] argue that "taking into account the widespread diffusion of social media and its ubiquity, it is important to grasp the role that these tools play in our society and what social, economic, and political impact they have on individuals, family ties, communities, and organizations".

The U\&G approach occupies a unique place within theories of mass communication and journalism. The digital landscape makes it clear that individuals are employing multiple sources of information, are members of diverse and specialized interest groups, and access both online and via mobile applications a wide range of media [4]. This proliferation of media types and sources suggests that different media outlets fulfill distinct and unique needs, making an analysis of U\&G essential [5]. Because the U\&G approach was developed in the 1940s, a group of scholars has questioned its utility for studying digital media. However, Ruggiero [6] has dismissed these concerns arguing that "any attempt to speculate on the future direction of mass communication theory must seriously include the U\&G approach". This suggests that the $U \& G$ approach can make a major contribution to research in an environment, where audiences are fragmented, the boundaries between producers and consumers blur [7], and user-generated content supplements, enhances, and competes with traditional media.

The U\&G approach developed as a counter perspective to much of the prevalent scholarship in the 1930s and 1940s on the relation between the mass media and their respective audiences. This body of work tended to stress the unidirectional and powerful effect of the mass media on consumers of content without much regard to audience members' agency, needs and preferences, cultural and economic backgrounds, and life styles [8]. This neglect led to a rather narrow and limited focus on the propagandistic effect of content on audiences and individuals' uncritical assimilation of mass media messages. For instance, the hypodermic needle model (also known as the magic bullet theory) conceptualized audience members as a homogeneous mass that consumes media messages in an uncritical and superficial manner [9]. These early models received considerable criticism for their simplistic views of how audience members use, consume, and make sense of media messages. These models were further refuted by the writings of McLuhan [10] and others at the Toronto School of Communication [11], as these authors shifted the debate in mass communication from one focused on simple effects of messages toward an understanding of media as complex social tools.

Quan-Haase and Young (forthcoming) [3] have identified three central tenants of the $U \& G$ approach that distinguish it from other approaches in mass communication and journalism:

(1) Conceptualization of the audience. Instead of viewing the mass audience as passive and neutral, it is conceived of as actively participating in audience's media choices and engaged in content selection, evaluation, and dissemination. The U\&G approach distinguishes between media preferences by specific social groups, such as infants, kids, youth, and seniors.

(2) Focus on what people do. The focus is on what people do with the media, how it becomes relevant in their everyday life, instead of

*Corresponding author: AnabelQuan-Haase, Associate Professor, University of Western Ontario, Canada, Tel: 519-661-2111 x81405; Fax: 519-661-3506, E-mail: aquan@uwo.ca

Received June 07, 2012; Accepted June 09, 2012; Published June 09, 2012

Citation: Quan-Haase A (2012) Is the Uses and Gratifications Approach Still Relevant in a Digital Society? Theoretical and Methodological Applications to Social Media. J Mass Commun Journalism 2:e124. doi:10.4172/2165-7912.1000e124

Copyright: (C) 2012 Quan-Haase A. This is an open-access article distributed under the terms of the Creative Commons Attribution License, which permits unrestricted use, distribution, and reproduction in any medium, provided the original author and source are credited. 
assuming that all consumers engage with the media in the same manner [12].

(3) Media gratifications sought and obtained. The term media gratifications refer to the personal needs that a medium can fulfill. Key is the distinction between those gratifications sought prior to employing the medium for the first time and those that are obtained after having adopted the medium [13]. Long-term usage patterns are influenced by the extent to which specific media can fulfill user needs.

These three central tenants make the U\&G approach relevant to the study of social media. One of the key areas of study in the U\&G approach is how individuals use media and integrate it into their everyday live routines and practices. As social media platforms continue to proliferate and apps for smart phones and tablets increase in diversity and functionality, individuals are adopting a multiplicity of sites, services, tools, games, etc. This makes it necessary to understand what digital tools they employ, when they use them during the day, and how these fit with their daily routines and practices [14]. With the increasing reliance on mobile technology from cell phones to smart phones to tablets (e.g., iPad, Samsung, etc.), it is of great relevance to explore how individuals access social media sites on the go and connect both to content, media outlets, and their social networks. Additionally, how an individual uses social media may largely depend on their level of concern for privacy [15]. Privacy concerns about who may access personal information and how this information is stored may influence how individuals present themselves on Facebook, Twitter, and other popular SNS, encouraging certain types of personal information to be disclosed. How much information and what types of information are revealed will in turn have an effect on the gratifications obtained from engaging in the platform $[3,16]$.

The study of gratifications has primarily focused on those gratifications obtained after adoption. The primary reason for this focus is methodological. Predicting what social media platform users will join next is difficult and as a result it is challenging to examine what motivates adoption in the first place [5,17]. Nonetheless, considering the large proliferation of competing site and services, an examination of why users adopt a specific social media tool can shed light on what characteristics and features individuals consider useful and fitting with their social and information needs [18]. It becomes increasingly important for scholars to identify what factors motivate individuals to test and adopt new platforms, and how to compare various platforms in terms of usability, gratifications, and satisfaction. The open source movement for instance has played an important role in providing services that are free of charge and can be modified, re-used, and re-appropriated under a wide range of licenses [7]. Quan-Haase and Young [5] compared the gratifications sought from Facebook and instant messaging and found friend recommendations as a key motivating factor for adopting Facebook ("friend suggested it"), followed by mass adoption by one's offline social network ("everyone I know is on Facebook") and social relationship maintenance ("help others keep in touch with me"). In a study of the gratifications sought of Bebo ${ }^{1}$, Dunne, Lawlor and Rowley [19] found three key factors that motivated adoption: 1) communication with others, 2) to make new friends, and 3) to alleviate boredom or escape.

A central area of investigation of the U\&G approach is the gratifications obtained from a medium after continued use. A number of studies have been conducted that have systematically investigated the

Bebo stands for "Blog Early, Blog Often" and is a SNS that provides a platform for users to share content, images, and even ask other users to respond to questions and surveys. gratifications obtained from social media use. For example, a 2001 study by Leung et al. [20] examined students' motivations for chatting on the instant messaging platform ICQ. This early study found that students used ICQ primarily for affection: to express appreciation, care for others' feelings, show encouragement, offer help, and show concern for others [20]. More recently, a number of studies have emerged examining the gratifications obtained from using SNSs, particularly Facebook. This research has found that affection, while a key motivation for using IM, is of less importance in SNSs [5]. In contrast to IM, SNSs are used to pass the time (i.e., for entertainment, relaxation and as a means of escape) [5,17], for social surveillance and social searching (i.e., to learn about others without their explicit knowledge) [15], and for relationship maintenance (i.e., reconnecting with friends and family and maintaining a connection with friends and family) [16]. This illustrates clear differences in gratifications obtained from each type of social media. While IM is typically dyadic and allows for interactive conversations in real-time that mirror, in some aspects, face-to-face communication, Facebook and other SNSs revolve around a profile and a series of asynchronous messages exchanged via private e-mail messages or wall posts. In this way, IM exchanges support feelings and intimacy and the development of close ties, whereas the communications in SNSs serve as a way for users to have fun and entertain themselves (see Table 1).

Another social media platform that has received considerable attention in the media is Twitter. Twitter is considered a microblog that allows individuals to connect and exchange 140 character long messages. Even though Twitter is different from Facebook in terms of how profiles are created and information is displayed, studies on Twitter's gratifications show some parallels. Chen [19] in her study of Twitter gratifications found that connecting to one's social network of friends, family and colleagues is one of the key factors for continued use. In the study, Chen [19] found that Twitter was also relevant for conveying information. While Facebook also helps in sharing information about

\begin{tabular}{|l|l|l|}
\hline I use Facebook ... & Facebook & Instant Messaging \\
\hline Pastime & & \\
\hline To kill time & $\checkmark$ & $\checkmark$ \\
\hline Because it is entertaining & $\checkmark$ & $\checkmark$ \\
\hline Because I enjoy it & $\checkmark$ & $\checkmark$ \\
\hline Because it is fun & $\checkmark$ & $\checkmark$ \\
\hline Because it is a pleasant rest & & $\checkmark$ \\
\hline Because it relaxes me & $\checkmark$ \\
\hline $\begin{array}{l}\text { To get away from pressures and responsibili- } \\
\text { ties }\end{array}$ & $\checkmark$ & \\
\hline To get away from what I am doing & $\checkmark$ & \\
\hline To put off something I should be doing & $\checkmark$ & \\
\hline Affection & & $\checkmark$ \\
\hline To thank people & & $\checkmark$ \\
\hline To let people know I care about them & $\checkmark$ & $\checkmark$ \\
\hline To show others encouragement & & $\checkmark$ \\
\hline To help others & & $\checkmark$ \\
\hline $\begin{array}{l}\text { To show others that I am concerned about } \\
\text { them }\end{array}$ & & $\checkmark$ \\
\hline Sociability & & \\
\hline To make friends of the opposite sex & & \\
\hline To be less inhibited chatting with strangers & & \\
\hline To meet people (new acquaintances) & & \\
\hline Social know & & \\
\hline $\begin{array}{l}\text { To feel involved with what's going on with } \\
\text { other people }\end{array}$ & $\checkmark$ & \\
\hline \\
\hline
\end{tabular}

Table 1: Gratifications Obtained from Facebook and Instant Messaging [3]. 
Citation: Quan-Haase A (2012) Is the Uses and Gratifications Approach Still Relevant in a Digital Society? Theoretical and Methodological Applications to Social Media. J Mass Commun Journalism 2:e124. doi:10.4172/2165-7912.1000e124

social events and events occurring in an individual's personal life, Twitter is often geared toward forwarding links to resources in addition to supporting relationship maintenance.

In conclusion, the U\&G approach continues to play a unique and important role in studies of communication, sociability, information science, and journalism. In particular with the increasing adoption of social media, the U\&G approach seems promising in providing a theoretical framework from which to examine what kinds of social media are adopted by what segments of the population, and what gratifications individuals obtain from their use of various social media platforms, sites, and services. The U\&G approach also provides a methodology from which user preferences and satisfactions can be compared across social media sites. This will help us better understand what motivates users to spent large amounts of time on these sites sharing, liking/disliking, forwarding, adding, and disseminating content.

\section{References}

1. Rainie L, Lenhart A, Smith A (2011) The tone of life on social networking sites. The Pew Internet and American Life Project.

2. Lenhart A, Madden M, Smith A, Purcell K, Zickuhr K, et al. (2011) Teens, kindness and cruelty on social network sites. The Pew Internet and American Life Project.

3. Quan-Haase A, Young AL (forthcoming) The uses and gratifications (U\&G) approach as a lens for studying social media practice. In Fortner R, Fackler M (Edn), International handbook of media and communication theory. Blackwell, Cambridge, MA

4. Miller C, Purcell K, Rosenstiel T (2012) $72 \%$ of Americans follow local news closely. The Pew Internet and American Life Project.

5. Quan-Haase A, Young AL (2010) Uses and gratifications of social media: A comparison of Facebook and instant messaging. Bulletin of Science, Technology and Society 30: 350-361.

6. Ruggiero TE (2000) Uses and gratifications theory in the 21st century. Mass Communication \& Society 3: 3-37.
7. Bruns A (2008)Blogs, Wikipedia, Second Life, and beyond: From production to produsage. Peter Lang, New York.

8. Blumler JG, Katz E (1974) The uses of mass communications: Current perspectives on gratifications research. Sage, Beverly Hills.

9. Quan-Haase A, Brown B (2012) Uses and gratifications. Danesi M (Edn) Encyclopedia of Media and Communication.Toronto, University of Toronto Press.

10. McLuhan M (1964) Understanding media: The extension of man. McGraw-Hill, New York.

11. De Kerckhove D (1989) McLuhan and the Toronto school of communication Canadian Journal of Communication 14: 73-79.

12. Katz E, Lazarsfeld PF (1964) Personal influence: The part played by people in the flow of mass communications. Free Press, New York.

13. Katz E, Gurevitch M, Haas H (1973) On the use of mass media for importan things. American Sociological Review 38: 164-181.

14. Quan-Haase A (2008) Instant messaging on campus: Use and integration in students' everyday communication. The Information Society 24: 105-115.

15. Young AL, Quan-Haase A (2009) Information revelation and internet privacy concerns on social network sites: A case study of Facebook. In JM Carro (Edn). Fourth International Conference on Communities and Technologies. University Park, PA, USA, 265-274. Dordrecht: Springer Verlag.

16. Joinson NA (2008) 'Looking at', 'looking up', or 'keeping up with' people: Motives and uses of Facebook. Proceedings of CHI'081027-1036.

17. Dunne A, Lawlor MA, Rowley J (2010) Young people's use of online social networking sites - a uses and gratifications perspective. Journal of Research in Interactive Marketing 4: 46-58.

18. Papacharissi Z, Mendelson A (2011) Toward a new(er) sociability: Uses, gratifications, and social capital on Facebook. In S. Papathanassopoulos (Edn), Media perspectives for the 21st century. Routledge, New York 212-230.

19. Chen GM (2011) Tweet this: A uses and gratifications perspective on how ac tive Twitter use gratifies a need to connect with others. Computers in Human Behavior 27: 755-762.

20. Leung L (2001) College student motives for chatting on ICQ. New Media and Society 3: 483-500. 